\title{
Acoustic measurements of a liquefied cohesive sediment bed under waves
}

\author{
R. Mosquera, V. Groposo, and F. Pedocchi \\ Instituto de Mecánica de los Fluidos e Ingeniería Ambiental (IMFIA), Facultad de Ingeniería, Universidad de la República, \\ Montevideo, Uruguay
}

Correspondence to: R. Mosquera (rmosquer@fing.edu.uy)

Received: 1 October 2013 - Revised: 31 December 2013 - Accepted: 13 January 2014 - Published: 1 April 2014

\begin{abstract}
In this article the response of a cohesive sediment deposit under the action of water waves is studied with the help of laboratory experiments and an analytical model. Under the same regular wave condition three different bed responses were observed depending on the degree of consolidation of the deposit: no bed motion, bed motion of the upper layer after the action of the first waves, and massive bed motion after several waves. The kinematic of the upper $3 \mathrm{~cm}$ of the deposit were measured with an ultrasound acoustic profiler, while the pore-water pressure inside the bed was simultaneously measured using several pore pressure sensors. A poro-elastic model was developed to interpret the experimental observations. The model showed that the amplitude of the shear stress increased down into the bed. Then it is possible that the lower layers of the deposit experience plastic deformations, while the upper layers present just elastic deformations. Since plastic deformations in the lower layers are necessary for pore pressure build-up, the analytical model was used to interpret the experimental results and to state that liquefaction of a self consolidated cohesive sediment bed would only occur if the bed yield stress falls within the range defined by the amplitude of the shear stress inside the bed.
\end{abstract}

\section{Introduction}

The erosion of cohesive sediment deposits presents significant differences with the erosion of non-cohesive deposits. One of the main differences is the strong dependence of the cohesive bed erosion on the previous consolidation process. Mehta (1991) characterized the erosion mechanisms of cohesive sediment beds into three types: surface erosion, when the flocs or aggregates are entrained one by one as a result of the hydrodynamic lift and drag; Mass erosion, when a slip surface is generated inside the deposit and all the material above this surface is mobilized; and Destabilization of the sediment-water interface, when processes within the bed induce the formation of fluid mud.

Two mechanism for the formation of fluid mud have been proposed in the literature, sudden failure due to the large shear stresses imposed by "large" waves on a "soft bed" and progressive pore pressure build-up under the successive action of "small" waves on a "partially consolidated bed". This article explores the necessary conditions that would lead to the occurrence of each of these mechanisms. The second of these two mechanisms is technically described as liquefaction of the bed due to pore pressure build-up. Terzaghi et al. (1996) established that the stress at any location inside a sediment-water mixture has two components: one component is a hydrostatic stress state that acts with equal intensity in every direction, which is associated to the pore-water pressure. The other component, called effective stress, is associated with the stress supported by the solid phase. The solid phase is considered the skeleton of the mixture and provides its shearing resistance.

Liquefaction of a sediment-water mixture is related to the increase of pore-water pressure and the corresponding decrease of the effective stress. When liquefaction occurs, the water-sediment mixture loses its shearing resistance and behaves as a dense fluid. During liquefaction, the mechanical characteristics of the sediment bed change so dramatically that marine structures fail, buried pipelines emerge, and navigation channels get silted in a matter of hours. Under the action of waves, liquefaction is a major concern in sediment 
beds with low permeability such as silt, clay or very fine sand (De Groot et al., 2006; Jeng, 2003).

Silt and clay water mixtures are usually referred as mud. For analytical purposes, mud can be considered to be a viscoelastic material, having an elastic response for small deformations and shear stresses, and a viscous response for large deformations (for an extense review see de Wit et al., 1994). These large deformations are associated with shear stresses $\tau$ overpassing a certain threshold, called yield stress $\tau_{\mathrm{Y}}$. Under oscillatory flow, the shear stresses could overpass the yield stress during part of the wave cycle producing non-elastic deformations in some regions of the bed. In high porosity and low permeability deposits, this non-elastic deformations may induce the progressive reorganization of sediment particles and the reduction of pore volume. This reduction may progressively lead to the increase (build-up) of the pore pressure and the associated reduction of the effective stresses, eventually triggering liquefaction (see for example the work of Sumer and Fredsøe, 2002, for non-cohesive sediments).

In this article we explore the liquefaction mechanism in a cohesive-sediment bed under the action of regular waves. For this aim we ran experiments in a laboratory wave flume, and simultaneously registered the pore pressure and the mud bed velocity. To our knowledge this is the first time these simultaneous measurements are performed, making it possible to clearly differentiate the two mechanisms that can generate fluid mud under the action of waves: sudden shear failure in soft deposits, and progressive pore pressure build-up in partially consolidated ones. For this second mechanism, a theoretical model that only considers elastic deformations of the bed is used to estimate the deformations within the bed, and to predict regions where non-elastic deformations of the bed and pore pressure build-up may occur.

\section{Theoretical model}

In order to have non-elastic deformations and pore pressure build-up, shear stress $\tau$ must be larger than the yield stress $\tau_{\mathrm{Y}}$ in some regions of the bed during part of the wave cycle. If the sediment grains are loosely packed, the shear stresses generated by the successive waves will gradually rearrange the grains, reducing of the pore volume, and if the permeability of the soil is low, increasing the pore-water pressure (Sumer and Fredsøe, 2002). To study this necessary condition for liquefaction, the shear stresses inside the bed are estimated assuming an elastic response of the bed. If $\tau$ remains smaller than $\tau_{Y}$ during the whole cycle, only elastic deformations would occur, the pore volume would not change after a complete wave cycle, and pore pressure build-up would not take place. However, if $\tau$ becomes larger than $\tau_{Y}$ at some point during the cycle, a permanent deformation of the bed will occur, the pore-water pressure may build-up and liquefaction would be eventually observed. Once liquefaction has occurred, the elastic model is not able to predict the actual stress anymore. However, the elastic model can be used to qualitatively explore the necessary conditions for liquefaction and interpret the experimental observations.

Yamamoto et al. (1978) studied the response of a poroelastic semi-infinite bed under regular water waves using a quasi-static model. Here the same set of equations is used, but for studying the response of a finite thickness poro-elastic bed. Furthermore, the equations are expressed in dimensionless form, defining a set of dimensionless parameters, which facilitates the psychical interpretation of the different terms in the equations, and their relevance for the occurrence of liquefaction. The case of a finite thickness poro-elastic bed was studied before by Spierenburg (1987). However, Spierenburg solutions were approximate, while the harmonic solutions presented here are exact. The detailed deduction of these exact harmonic solutions exceeds the scope of this article and can be found in Mosquera (2013).

Based on the model developed by Biot (1941) and assuming that the pore-water flow follows Darcy's law, the following equation for the conservation of pore-water can be written

$$
\frac{k}{\gamma} \Delta p=\frac{n}{K^{\prime}} \frac{\partial p}{\partial t}+\frac{\partial \epsilon}{\partial t}
$$

where $k$ is the coefficient of permeability of the soil, $\gamma$ is the unit weight of the pore-water, $p$ is the pore-water pressure, $n$ is the porosity, $K^{\prime}$ is the apparent bulk modulus of porewater, $t$ is the time, and $\epsilon$ is the volume strain of the porous medium. Considering that the mud behaves in an elastic way, the equations of equilibrium may be expressed as

$G \Delta u+\frac{G}{1-2 v} \frac{\partial \epsilon}{\partial x}=\frac{\partial p}{\partial x}$,
$G \Delta w+\frac{G}{1-2 v} \frac{\partial \epsilon}{\partial z}=\frac{\partial p}{\partial z}$,

where $u$ and $w$ are the horizontal and vertical components of the mud displacement, respectively; $v$ is the Poisson's ratio of the mud and $G$ is its shear modulus. Remembering the definition of the volume strain

$\epsilon=\frac{\partial u}{\partial x}+\frac{\partial w}{\partial z}$,

now we have four equations from Eqs. (1) to (4), one for each unknown variable ( $p, u, w$ and $\epsilon$ ). Additionally, effective stresses within the bed can be related to the bed strains using Hooke's law

$$
\begin{aligned}
& \sigma_{x}^{\prime}=2 G\left(\frac{\partial u}{\partial x}+\frac{v}{1-2 v} \epsilon\right), \\
& \sigma_{z}^{\prime}=2 G\left(\frac{\partial w}{\partial z}+\frac{v}{1-2 v} \epsilon\right), \\
& \tau_{x z}=G\left(\frac{\partial u}{\partial z}+\frac{\partial w}{\partial x}\right),
\end{aligned}
$$


where $\sigma_{x}^{\prime}$ and $\sigma_{z}^{\prime}$ are the effective normal stress in horizontal and vertical directions respectively and $\tau_{x z}$ is the shear stress on a vertical or horizontal plane.

In order to solve the mud motion and the pore-water pressure field, it is necessary to know the boundary conditions of the problem. A dynamic condition is used for the watermud interface. Since cohesive sediment beds can be considered smooth, the shear stress friction factor is relatively low. For the experimental conditions considered in this article, it can be shown that tangential stresses are at least one order of magnitude smaller than $\tau_{Y}$, and as a first approximation waves can be considered to just impose normal stresses on the bed.

Assuming that the pressure varies continuously from the water column into the top pores of the bed, the boundary conditions at the mud-water interface are obtained

$\sigma_{z}^{\prime}=0$

$\tau_{x z}=0$,

$p=P_{0} \cos (\lambda x-\omega t)$,

where $\lambda$ is the wave number and $\omega$ the angular frequency of the surface waves, and $P_{0}$ is the pressure amplitude imposed by the waves on the bed surface. $P_{0}$ is calculated using the Airy wave theory as

$P_{0}=\frac{\gamma H}{2 \cosh (\lambda h)}$.

The lower boundary of the mud deposit is considered rigid and impermeable, allowing for no vertical displacement and no vertical pore-water flux. Additionally, two possible conditions for this boundary are considered: complete adherence at the rigid boundary and a perfectly slipping boundary.

For the complete adherence case

$u=0$,

and for the perfect-slip plane case

$\tau_{x z}=0$.

The first two boundary conditions at the lower boundary are

$w=0$,

$\frac{\partial p}{\partial z}=0$.

Taking scales for the different variables, it could be shown that, apart from the Poisson's ratio $v$, the problem is defined by three dimensionless numbers

$d \lambda$,

$\kappa=\frac{1-v}{1-2 v} \frac{2 n G}{K^{\prime}}$,

$\delta=\frac{1-v}{1-2 v} \frac{2 k G}{\gamma d^{2} \omega(\kappa+1)}$. $d \lambda$ is the geometric ratio between the bed thickness and the wave length, $\kappa$ is the ratio between the water compressibility and sediment bed compressibility, and $\delta$ is the ratio between the ability of the water to flow within the bed and the pore pressure variation along the wave cycle. For a cohesive sediment bed saturated with water, both permeability $k$ and shear modulus $G$ are small, and therefore both $\kappa$ and $\delta$ can be considered small quantities.

Length scales for $u$ and $w$ can be conveniently defined as

$U_{0}=\frac{1-2 v}{1-v} \frac{P_{0}}{2 G \lambda}$,

and

$W_{0}=\frac{1-2 v}{1-v} \frac{d P_{0}}{2 G}$,

respectively.

Finally a system of equations and boundary conditions in dimensionless form can be solved for a given set of the four dimensionless numbers $(v=0.3, d \lambda=0.512, \kappa=$ $\left.2.65 \cdot 10^{-4}, \delta=1.80 \cdot 10^{-3}\right)$. These numbers were obtained from Eqs. (16) to (18) using the following characteristics for the mud bed: $k=10^{-6} \mathrm{~ms}^{-1}, n=0.3, v=0.3, G=$ $4.8 \cdot 10^{5} \mathrm{Nm}^{-2}, \gamma=9800 \mathrm{Nm}^{-3}, K^{\prime}=1.9 \cdot 10^{8} \mathrm{Nm}^{-2}$, and $d=0.15 \mathrm{~m}$; under the following wave forcing: $h=0.176 \mathrm{~m}$, $\omega=4.24 \mathrm{rads}^{-1}, H=0.10 \mathrm{~m}$, giving $\lambda=3.41 \mathrm{~m}^{-1}, P_{0}=$ $413 \mathrm{~Pa}, U_{0}=7.20 \cdot 10^{-5} \mathrm{~m}$ and $W_{0}=3.69 \cdot 10^{-5} \mathrm{~m}$. All the characteristics are considered uniform within the bed. The numerical values were taken from the literature and are considered representative of the experimental conditions discussed here.

Under these conditions it was possible to determine the profiles of $p, u, w$ and the effective stress state $\left(\sigma_{x}^{\prime}, \sigma_{z}^{\prime}\right.$ and $\left.\tau_{x z}\right)$ for the two possible bottom boundary conditions. Figure 1 shows the dimensionless amplitude profiles of these magnitudes. Once the stress state is known, the amplitude of the maximum shear stress at a point for any plane direction $\tau$ can be computed. For both bottom boundary conditions the $\tau$ profile is found to be non-zero at the top layer of the deposit, where $\tau=\tau_{0}$. For the complete adherence case, the $\tau$ profile has a local maximum and a local minimum, finally increasing toward the bottom of the deposit, where $\tau=\tau_{\mathrm{d}}$. For the perfect slip case, the $\tau$ profile monotonically increases toward the bottom of the deposit. It is interesting to note that $\tau$ reaches higher values for the perfect-slip case that for the complete adherence case showing the relevance of the phase shift among the different components of the shear stress tensor.

Although the $\tau$ profile was found under the hypothesis of pure elastic motion, some relevant observations can be made regarding the possible occurrence of liquefaction in regions where the maximum shear stress exceeds the mud yield stress $\tau_{\mathrm{Y}}$, and non-elastic deformations may occur. Comparing the mud yield stress $\tau_{Y}$ with the shear stress profile $\tau$, three scenarios may be defined: 

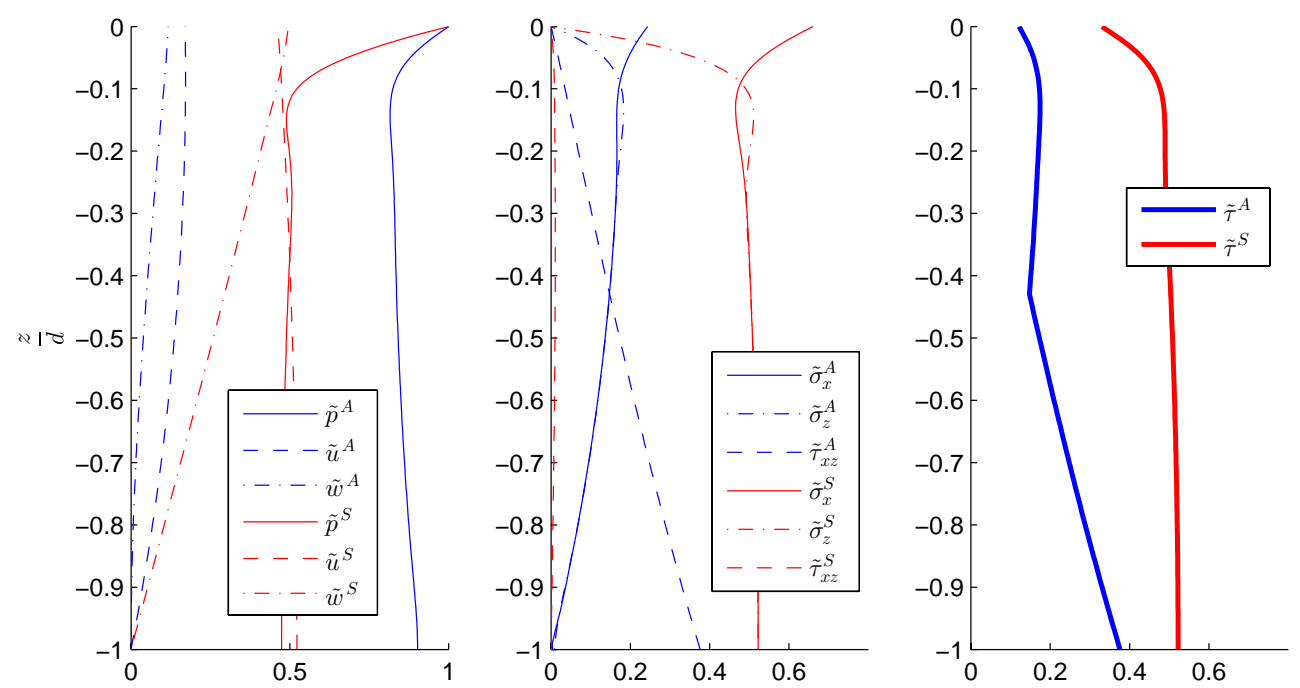

Fig. 1. Non dimensional profiles of $\tilde{p}=\frac{|p|}{P_{0}}, \tilde{u}=\frac{|u|}{U_{0}}, \tilde{w}=\frac{|w|}{W_{0}}, \tilde{\sigma}_{x}^{\prime}=\frac{\left|\sigma_{x}^{\prime}\right|}{P_{0}}, \tilde{\sigma}_{z}^{\prime}=\frac{\left|\sigma_{z}^{\prime}\right|}{P_{0}}, \tilde{\tau}_{x z}=\frac{\left|\tau_{x z}\right|}{P_{0}}$ and maximum shear stress amplitude for both bottom boundary conditions, complete adherence $(A)$ and perfect slip $(S)$.

- If $\tau_{0}>\tau_{\mathrm{Y}}$ the top layers of the deposit will flow during part of the wave cycle. This behavior will be observed immediately after the first wave acts on the deposit. Since the top layers are flowing, it is easier for porewater to liberate its pressure, reducing the chances of pressure build-up.

- If $\tau_{\mathrm{d}}>\tau_{\mathrm{Y}}>\tau_{0}$, plastic deformations are observed in the lower layers where $\tau>\tau_{\mathrm{Y}}$. In this region the permanent deformations will lead to the reorganization of the soil skeleton and, depending on the mud permeability, pore pressure build-up would take place.

- If $\tau<\tau_{\mathrm{Y}}$ over the whole deposit, only elastic deformations will be expected and no pore pressure build-up can occur.

\section{Methods}

Previous laboratory work regarding liquefaction focused on measuring pore-water pressure, due to the importance of this variable on the phenomena. For the experiments shown here a laboratory acoustic velocity meter was used to measure the mud flow simultaneously with the pore pressure. These velocity meter have high spatial and temporal resolution, and are practically non-intrusive. Most acoustic instruments are designed to measure in water, but it is possible to use them to perform velocity measurements in concentrated sediment mixtures (Gratiot et al., 2000; Salehi and Strom, 2011). For the present experiments, velocity measurements through the water column and inside the upper layers of the deposit (first $3 \mathrm{~cm}$ ) were performed using an Ultrasonic Velocity Profiler (UVP) produced by MetFlow (Pedocchi and García, 2011) equipped with a $2 \mathrm{MHz}$ transducer. The trans- ducer was placed $12 \mathrm{~cm}$ above the mud deposit at a $55^{\circ}$ angle with the horizontal. It should be pointed out that the UVP measures the projection of the velocity vector on the direction of the sensor. However, in shallow waters the water motion can be considered horizontal near the bed and the projection of the velocity measured by the UVP can be considered a good proxy for the actual velocity.

The experiments presented here were performed in a wave flume located at the Instituto de Mecánica de los Fluidos e Ingeniería Ambiental (IMFIA). The flume is $0.51 \mathrm{~m}$ wide, $0.76 \mathrm{~m}$ deep, and $16 \mathrm{~m}$ long. The flume bottom was modified by placing a false bottom of $15 \mathrm{~cm}$ high. The false bottom covered the entire flume, with the exception of a $1.8 \mathrm{~m}$ gap in the middle of the flume (Fig. 2). At the front of the wavemaker, a $2.8 \mathrm{~m}$ long ramp allowed a smooth transition from the flume bottom towards the false bottom. At the opposite end of the flume a permeable beach absorbed the incident waves. The beach reflection in terms of the wave energy was close to $1 \%$ (Mosquera and Pedocchi, 2013). All five experiments described next were performed under the same hydrodynamics conditions: regular waves generated by a piston-type wavemaker oscillating with a period $T=1.48 \mathrm{~s}$, and producing $H=10 \mathrm{~cm}$ hight waves in a water depth $h=17.6 \mathrm{~cm}$.

Seven wet-wet pore pressure transducers, model 26PCAFA6D produced by Honeywell, were mounted at different locations inside the mud bed as shown in Fig. 2. PVC tubing, 3/16inch $(4.8 \mathrm{~mm})$ internal diameter and $9 / 32$ inch $(7.1 \mathrm{~mm})$ external diameter, was used to connect the measurement points $\mathrm{P \#}$ with the pressure transducers. The measuring range of the pressure transducers was $\pm 0.70 \mathrm{mH}_{2} \mathrm{O}( \pm 6.9 \mathrm{KPa})$. Iron pieces were attached to the flume bottom to strongly hold the piping and avoid their motion. The air from inside the tubing was carefully drained 

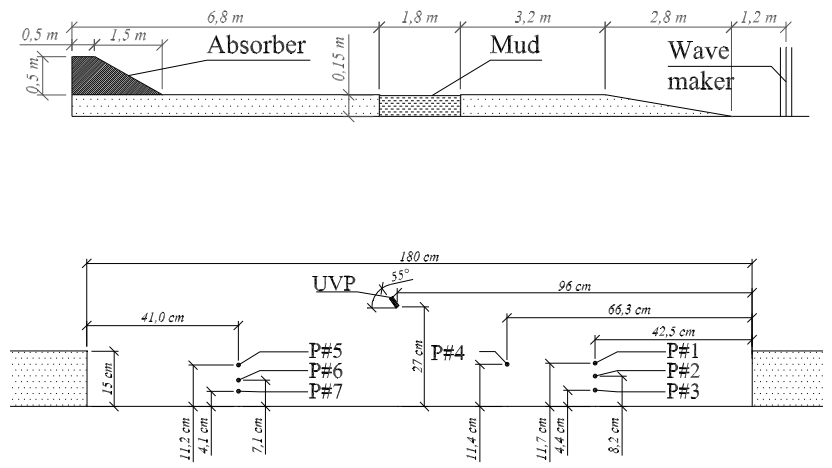

Fig. 2. Scheme of the wave flume and the experimental set-up, showing the location of the UVP transducer and the seven pore pressure sensors.

in order to obtain high quality measurements. At the end of each tubing a filter was placed to prevent sediments from flowing into the measuring system and care was taken to avoid the filters from getting clogged with sediment.

Artificial kaolinite clay was used for the mud deposits. The sediment density was $2635 \mathrm{~kg} \mathrm{~m}^{-3}$. Its granulometry was determined by two different techniques, with ASTM (2007a) standard method and with a laser diffraction technique using a Mastersizer 2000 produced by Malvern. Results were in good agreement, giving a mean diameter of $7.1 \mu \mathrm{m}$ and a standard deviation of $0.2 \mathrm{~mm}$. Also ASTM (2007b) and ASTM $(2007 \mathrm{c})$ standards where applied for the determination of a liquid limit of 24 and a plastic limit of 18, an inorganic clay of low plasticity according to Casagrande (1932) classification. The density of the mud was determined before the experiments by extracting a sample of the upper layers of the deposit, and applying the ASTM (2010) and ASTM (2009) standards, with the help of a LJ16 Infrared Dryer produced by Mettler Toledo.

In order to produce beds that would develop different responses under the same wave forcing several mud deposits were prepared as follows. After the flume was filled with water, the sediments were mixed with the water in the water column. Two partition walls were used to prevent the sediment mixture from flowing away from the bottom depression area during the mixing, sedimentation, and consolidation of the bed. Different consolidation times, ranging from days to weeks, were used to generate deposits with different densities and yield stresses. Experiment \# 1 had a bed density of $1548 \mathrm{~kg} \mathrm{~m}^{-3}$, \#2 $1599 \mathrm{~kg} \mathrm{~m}^{-3}, \# 31738 \mathrm{~kg} \mathrm{~m}^{-3}$, \#4 $1608 \mathrm{~kg} \mathrm{~m}^{-3}$ and \#5 $1660 \mathrm{~kg} \mathrm{~m}^{-3}$. Experiment \#3 was performed over the bed left by Experiment \#2.

\section{Results and discussion}

Figure 3 summarizes the results of the experiments. The top colored charts in this figure show the velocity profile series measured with the UVP during sixty waves. The black an

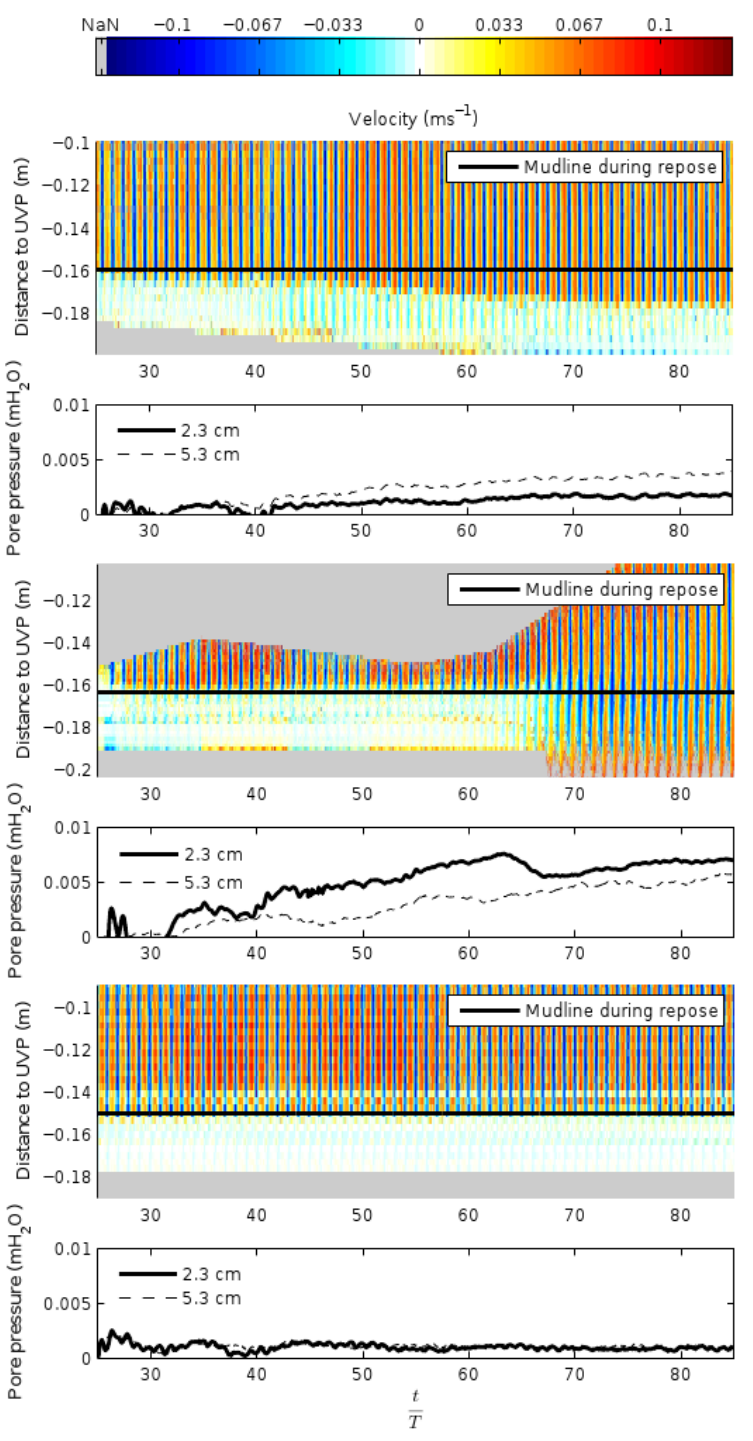

Fig. 3. From top to bottom: Experiment \#1 $\left(\rho_{\mathrm{b}}=1548 \mathrm{~kg} \mathrm{~m}^{-3}\right)$, progressive motion of the bed starting from the upper layers, corresponding to the $\tau_{\mathrm{Y}}<\tau_{0}$ condition. Experiment \#4 $\left(\rho_{\mathrm{b}}=1608 \mathrm{~kg} \mathrm{~m}^{-3}\right)$, liquefaction of the bed due to pore pressure build-up, corresponding to the $\tau_{\mathrm{d}}>\tau_{\mathrm{Y}}>\tau_{0}$ condition. Experiment $\# 3\left(\rho_{\mathrm{b}}=1738 \mathrm{kgm}^{-3}\right)$, no mobilization of the bed, corresponding to the $\tau_{\mathrm{Y}}>\tau_{\mathrm{d}}$ condition. The colored charts show the velocity profile series measured with the UVP at each experiment during sixty waves, the black line indicates the location of the top of the bed at the beginning of the experiment, cold colours indicate velocities towards the sensor and warm colours away from the sensor, grey zones indicate low quality data due to low acoustic backscatter intensity. The black an white charts shows the period-averaged porewater pressure for two different heights $(2.3 \mathrm{~cm}$ and $5.3 \mathrm{~cm}$ below the initial mud-water interface). 
white charts show the period-averaged pore-water pressure for two different heights $(2.3 \mathrm{~cm}$ and $5.3 \mathrm{~cm}$ below the initial mud-water interface). For the present experiments the maximum shear stress at the upper layer was of the order of $\tau_{0}=50 \mathrm{~Pa}$. Three types of bed response were observed in the experiments: motion of the upper layers of the deposit, starting with the first waves; liquefaction of the bed, after several waves had pass over the deposit; and "no motion".

The first response (motion of the upper layers) was observed during Experiment \#1 $\left(\rho_{\mathrm{b}}=1548 \mathrm{~kg} \mathrm{~m}^{-3}\right)$, which had the lowest bed density. The bed motion started on the upper layers with the first wave and slowly progressed down into the deposit. Figure 1 illustrates this response, which corresponds to the $\tau_{0}>\tau_{Y}$ case presented at the end of Sect. 2 . For this case the shear stress overpasses the yield stress and the top layer fails as the first wave travels over the bed. As the first layer fails, the elastic model does not apply to that layer anymore. However, it may still be applied to the next layer down, which will also fail. This process can therefore progress, slowly mobilizing successive layers of the deposit as it was observed in this experiment. A slight build-up of pore-water pressure was observed during Experiment \#1 on both sensors but it was not large enough to produce liquefaction.

The second response (liquefaction of the bed) was observed in Experiments \#2 and \#4 $\left(\rho_{\mathrm{b}}=1599 \mathrm{~kg} \mathrm{~m}^{-3}\right.$ and $\rho_{\mathrm{b}}=1608 \mathrm{~kg} \mathrm{~m}^{-3}$ respectively). A gradual build-up of pore pressure was measured by the pressure sensors and no motion on the top layers was measured by the UVP. These experiments can be considered to fall in the $\tau_{\mathrm{Y}}>\tau_{0}$ class. The shear stresses near the surface were only able to produce elastic deformations. However, as the shear stress increases with depth, the lower layers suffered plastic deformations. Then, the successive action of waves slowly reduced the voids volume in these layers increasing the pore-water pressure. After tens of waves had passed over the bed, the entire bed abruptly started to move and the pore pressure at $2.3 \mathrm{~cm}$ sensor descended to a value near the recorded value by the $5.3 \mathrm{~cm}$ depth sensor. The difference between Experiments \#2 and \#4 was the number of waves that induced liquefaction, in Experiment \#2 (not shown here) only ten waves were needed. It is interesting to note that the $2.3 \mathrm{~cm}$ sensor presented a faster pore pressure build-up. This can be explained in part because the yield stress of the bed probably increases with depth, instead of being constant as supposed here. Additionally, if complete adherence at the bottom of the deposit is considered, Fig. 1 shows that this sensor was located close to $\tau$ 's local maximum, where the largest plastic deformations should be expected.

Finally, during Experiments \#3 and \#5 $\left(\rho_{\mathrm{b}}=1738 \mathrm{~kg} \mathrm{~m}^{-3}\right.$ and $\rho_{\mathrm{b}}=1660 \mathrm{~kg} \mathrm{~m}^{-3}$ respectively) neither bed motion nor significant pore-water pressure built up were observed, even after hundreds of waves had passed over the bed. These two experiments are considered to had fallen in the $\tau_{\mathrm{d}}<\tau_{\mathrm{Y}}$ case and therefore neither bed plastic deformation nor pore pressure build-up were possible.

\section{Conclusions}

For some time, researchers have suggested two mechanisms to explain the generation of fluid mud under waves: progressive pore pressure build-up in partially consolidated deposits, and sudden shear failure in soft deposits. Both mechanisms were observed in the experiments presented here. And an explanation for each of these responses was discussed depending on the ratio between the bed yield stress and the shear stress profile imposed inside the bed by the action of waves. Experiments \#2 and \#4 are particularly relevant since they showed that a partially consolidated bed under moderate waves can suddenly get mobilized, even though the individual waves were not able to mobilize the deposit. This type of fatigue failure is particularly dangerous since the usual maximum wave hight criteria would fail to predict it.

The simultaneous measurements of the bed velocity field with the UVP and the pore-water pressure with the pressure transducers, made possible to clearly identify the failure mechanisms. The poro-elastic solutions for the bed deformation showed that the shear stress increases down into a finite thickness bed, and plastic deformations may occur in the lower layers of the deposit while only elastic deformations are possible in the top layers. If the permeability of the deposit is low enough, these plastic deformations of the lower layers would induce the build-up of pore pressure and lead to the liquefaction of the mud bed.

Acknowledgements. We would like to thank the Agencia Nacional de Investigación e Innovación (ANII), Uruguay, for the financial support given to the first author under its scholarships program "Posgrados Nacionales" (BE_POS_2010_1_2578, 2010). Additionally part of the work presented here was done under the grant of PR_FMV_2009_1_1890 also from the ANII, this support is greatly appreciated. The authors would like to thank the IMFIA machine shop staff (D. Barboza and R. Zouko) for their help with the experimental set-up. We would also like to thank G. Sanchez and A. Bologna from the Instituto de Ingeniería Química of Facultad de Ingeniería, Uruguay; and Susana Vinzón and Marcos Gallo from the Area de Engenharia Costeira of the Universidad Federal de Río de Janeiro (UFRJ), Brasil for their help with the characterization of the sediment samples. The collaboration with the UFRJ was possible thanks to the CAPES-UdelaR academic exchange program (026/2010) of the CAPES Foundation, Brazil, and Universidad de la República, Uruguay. 


\section{References}

ASTM: D422-63 Standard Test Method for Particle-Size Analysis of Soils, American Society for Testing and Materials, West Conshohocken, PA, 2007a.

ASTM: D423-66 Method of Test for Liquid Limit of Soils, American Society for Testing and Materials, West Conshohocken, PA, 2007b.

ASTM: D424-54 Standard Method of Test for Plastic Limit, American Society for Testing and Materials, West Conshohocken, PA, 2007c.

ASTM: D7263-09 Standard Test Methods for Laboratory Determination of Density (Unit Weight) of Soil Specimens, American Society for Testing and Materials, West Conshohocken, PA, 2009.

ASTM: D2216-10 Standard Test Methods for Laboratory Determination of Water (Moisture) Content of Soil and Rock by Mass, American Society for Testing and Materials, West Conshohocken, PA, 2010.

Biot, M.: General theory of three-dimensional consolidation, J. Appl. Phys., 12, 155-164, 1941.

Casagrande, A.: The structure of clay and its importance in foundation engineering, Journal of Boston Society of Civil Engineers, 419, 168-209, 1932.

De Groot, M., Bolton, M., Foray, P., Meijers, P., Palmer, A., Sandven, R., Sawicki, A., and Teh, T.: Physics of liquefaction phenomena around marine structures, J. Waterw. Port C.-ASCE, 132, 227-243, 2006.

de Wit, P., Kranenburg, C., and Winterwerp, J.: Liquefaction and erosion of mud due to waves and current: Experiments on China Clay, Internal report, 128 pp., Delft University of Technology, the Netherlands, 1994
Gratiot, N., Mory, M., and Auchère, D.: An acoustic Doppler velocimeter (ADV) for the characterisation of turbulence in concentrated fluid mud, Cont. Shelf Res., 20, 1551-1567, 2000.

Jeng, D. S.: Wave-induced sea floor dynamics, Appl. Mech. Rev., 56, 407-429, 2003.

Mehta, A.: Review notes on cohesive sediment erosion, Coastal Sediments 1991, 40-53, 1991.

Mosquera, R.: Generalized response of a poro-elastic bed to water waves, Instituto de Mecánica de los Fluidos, Internal Report, 2013.

Mosquera, R. and Pedocchi, F.: Decomposition of incident and reflected surface waves using an Ultrasonic Velocity Profiler, Coast. Eng., 71, 52-59, 2013.

Pedocchi, F. and García, M. H.: Acoustic measurement of suspended sediment concentration profiles in an oscillatory boundary layer, Cont. Shelf Res., 46, 87-95, doi:10.1016/j.csr.2011.05.013, 2011.

Salehi, M. and Strom, K.: Using velocimeter signal to noise ratio as a surrogate measure of suspended mud concentration, Cont. Shelf Res., 31, 1020-1032, 2011.

Spierenburg, S. E. J.: Seabed Response to Water Waves, Ph.d.dissertation, Delft University of Technology, the Netherlands, 1987.

Sumer, B. and Fredsøe, J.: The Mechanics of Scour in the Marine Environment, World Scientific, 2002.

Terzaghi, K., Peck, R., and Mesri, G.: Soil mechanics in engineering practice, Vol. 3rd Edn., Wiley, 1996.

Yamamoto, T., Koning, H., Sellmeijer, H., and van Hijum, E.: On the response of a poro-elastic bed to water waves, J. Fluid Mech., 87, 193-206, 1978. 